\title{
Impact of Different Bacterial Strains on the Production, Composition, and Properties of Novel Polyhydroxyalkanoates Using Crude Palm Oil as Substrate
}

\author{
P. R. Rodrigues" and J. I. Druzian \\ Federal University of Bahia, Graduate Program in Chemical Engineering, \\ Rua Aristides Novis, n 2, $2^{\text {nd }}$ floor, Federação. Postal code: 40210-630, \\ Salvador - BA, Brazil
}

doi: 10.15255/CABEQ.2017.1207

Original scientific paper Received: August 31, 2017 Accepted: February 13, 2018

\begin{abstract}
Polyhydroxyalkanoates (PHAs) are a group of biodegradable polymers produced from renewable sources by prokaryotic biocatalysts, accumulated intracellularly for energy and carbon storage. In the present study, production and characterization of PHAs synthetized by Cupriavidus necator (IPT 026 and IPT 027) and Burkholderia cepacia (IPT 119 and IPT 400) were evaluated using crude palm oil $\left(\mathrm{C}_{16: 0}=26.44 \%, \mathrm{C}_{18: 1}=54.50 \%\right.$, $\left.\mathrm{C}_{18: 2}=13.41 \%\right)$ as substrate $\left(15 \mathrm{~g} \mathrm{~L}^{-1}\right.$ crude palm oil, $\left.\mathrm{pH} 7.0,180 \mathrm{rpm}, 72 \mathrm{~h}\right)$. All strains were able to synthesize novel PHA copolymers $\left(0.10-1.45 \mathrm{~g} \mathrm{~L}^{-1}\right)$, and IPT 027 displayed the highest production. Copolymers monomeric composition $\left(M_{\mathrm{w}}=173.78-389.30 \mathrm{kDa}\right)$ was comprised mostly of hydroxyhexadecanoate (41.43-53.15\%) and hydroxy-9-octadecenoate (14.91-29.61 \%). PHAs were predominantly amorphous, showed low polydispersity, and good thermal stability $\left(T_{\text {onset }} \geq 283^{\circ} \mathrm{C}\right)$, which increased proportionally to crystallinity. Crude palm oil constitutes an emerging alternative for PHAs production, and microorganism strains strongly affect polymer accumulation, monomeric composition, molar mass, and properties.
\end{abstract}

Key words:

Elaeis guineensis, bioconversion, PHA, characterization

\section{Introduction}

Polyhydroxyalkanoates (PHAs) are a group of bio-polyesters that have been largely studied due to their physicochemical characteristics and biodegradability. Their properties are comparable to those exhibited by traditional synthetic polyesters (petroleum based) and they are decomposed by naturally occurring prokaryotes, such as archaea and bacteria, into carbon dioxide and water ${ }^{1,2,3}$.

The biopolymers synthesis occurs by numerous prokaryotes, intracellularly. PHAs yields and properties are very dependent on the synthesizer microbe, commonly, a feast/famine feed strategy is used to enrich PHA accumulation within the producer microorganism cells, stimulating growth phase (feast period) and then shifting to favor polymer accumulation (famine period), where limitation of at least one nutrient necessary for cell multiplication (such as $\mathrm{N}, \mathrm{P}, \mathrm{Mg}$ or $\mathrm{Fe}$ ) is applied ${ }^{4,5}$.

High costs of PHAs production is a limiting factor to their applications and competitiveness against synthetic plastics. Therefore, these expenses

"Corresponding author: plinioeng@hotmail.com should be reduced to enhance economical sustainability. An approach to attenuate this problem is to use alternative and cheap substrates for the bioconversion, since customary ones such as sucrose, glucose and starch represent a major expense in the biomaterials production chain, among other problematic matters associated with their use ${ }^{6,7}$.

Substrates such as sugarcane molasses, fermented cheese whey, hemicellulose hydrolysates, and industrial wastes are being reported as alternative low-cost carbon sources for PHA production $^{8,9,10}$. Additionally, plant oil biomass and its related products have been reported to be very suitable carbon sources for PHA synthesis using a variety of microorganisms, revealing to be better substrates for the polymer production than sugars, carbon sources more traditionally used ${ }^{11,12,13,14}$

Plant oils contain higher carbon content per weight than sugars, suggesting a PHA yield of at least two times higher ${ }^{15}$. They are catabolized via $\beta$-oxidation cycle to produce polymers of different chain lengths ${ }^{12}$. The fatty acids are first converted to enoyl-CoA in the mentioned cycle, and then transformed to R-3-hydroxyacyl-CoA, polymerization precursor, by R-3-hydroxyacyl-CoA hydratase. Lastly, PHA polymerization is catalyzed by PHA synthase $^{16,17}$. 
Palm oil is one of the most important crops of agricultural oil production in the world, since its yield is about five times greater than that of oilseeds, such as soybean and rapeseed, per unit of planted area ${ }^{18}$.

Although the palm oil industry causes some controversies due to its impact on the environment and ecosystems, the rising and unyielding pressure of population growth and the need for food, biofuels and bioplastics motivate an immediate step for good management practices of environmentally friendly operations (plantation and milling) while intensifying the oil yields for a more sustainable production and fulfilling the future demand ${ }^{19,20}$.

In this context, the present study aimed to produce and characterize PHA using crude palm oil (Elaeis guineensis) as an alternative substrate for the submerged cultivation of whole cell biocatalysts Burkholderia cepacia (IPT 119 and IPT 400) and Cupriavidus necator (IPT 026 and IPT 027), intending to implement more viable biotechnological methods following market demand for biopolymers with suitable technological properties.

\section{Materials and methods}

\section{Bacterial strains}

Cupriavidus necator IPT 026 and IPT 027, and Burkholderia cepacia IPT 400 and IPT 119 were supplied by the Institute for Technological Research (IPT), in São Paulo, Brazil. The bacteria were grown at $33{ }^{\circ} \mathrm{C}$ in nutrient broth, maintained on nutrient agar (NA) at $4{ }^{\circ} \mathrm{C}$, and transferred to new plates every 15 days.

\section{Main carbon source}

Crude palm oil (Elaeis guineensis) was acquired in the trade market of Salvador-BA, Brazil and stored at $4{ }^{\circ} \mathrm{C}$, protected from light, for preservation.

\section{Chemical composition of the substrate}

Total carbon (C) content was determined according to Nelson and Sommers ${ }^{21}$ publication. Fatty acid profile was determined by the capillary column gas chromatographic method according to Joseph and Ackman ${ }^{22}$ and Nascimento et al. ${ }^{23}$ Separation of the methyl esters in the fatty acids was performed using gas chromatography (Varian 3800) with a flame ionization detector (GC-FID) and a fused silica gas chromatography capillary column EliteWAX $(30 \mathrm{~m} \times 0.32 \mathrm{~mm} \times 0.25 \mu \mathrm{m})$. Quantification of fatty acids, expressed in milligrams per $100 \mathrm{~g}$ sample, was performed by the addition of an internal standard (C23:0 Sigma ${ }^{\circledR}$, USA) according to Joseph and Ackman $^{22}$ and calculated using Eq. (1).

$\underset{(\mathrm{mg} / 100 \mathrm{mg} \text { sample })}{\text { Concentration }}=\frac{\mathrm{A}_{\mathrm{FA}} \cdot \mathrm{M}_{\mathrm{IS}} \cdot \mathrm{F} \cdot \mathrm{C}_{\mathrm{TL}}}{\mathrm{A}_{\mathrm{IS}} \cdot \mathrm{M} \cdot \mathrm{F}_{\mathrm{FA}}} \cdot 1000$

where:

$\mathrm{AFA}=$ area of fatty acid methyl ester peak in the chromatogram of the sample;

MIS = weight (in milligrams) of the internal standard added to the sample;

$\mathrm{F}=$ correction factor of fatty acid methyl ester to fatty acid;

$\mathrm{CTL}=$ percentage composition of total lipids from the sample;

AIS $=$ area of internal standard fatty acid methyl ester peak in the chromatogram of the sample;

$\mathrm{M}=$ sample mass (in milligrams);

FFA $=$ correction factor response of each fatty acid methyl ester ionization detector, relative to C23:0.

\section{PHA production}

\section{Culture media}

Bacteria were stored at $4{ }^{\circ} \mathrm{C}$ in nutrient agar (NA) composed of $5.0 \mathrm{~g} \mathrm{~L}^{-1}$ meat peptone, $3.0 \mathrm{~g} \mathrm{~L}^{-1}$ beef extract, and $3.75 \mathrm{~g} \mathrm{~L}^{-1}$ agar. Inoculation was performed in nutrient broth (NB), composed of 5.0 $\mathrm{g} \mathrm{L}^{-1}$ bacteriological peptone, $3.0 \mathrm{~g} \mathrm{~L}^{-1}$ beef extract, and distilled water, over a period of $24 \mathrm{~h}$. PHA was produced using a two-stage cultivation strategy as described by Wang et al. ${ }^{24}$ and Campos et al. ${ }^{25}$

Mineral media were used for the first culture (FC), with no nitrogen limitation, and as the second culture (SC), with nitrogen limitation. Both FC and $\mathrm{SC}$ were composed of nitrilotriacetic acid $\left(0.1 \mathrm{~g} \mathrm{~L}^{-1}\right)$, ferrous ammonium citrate $\left(0.04 \mathrm{~g} \mathrm{~L}^{-1}\right), \mathrm{MgSO}_{4} \cdot 7 \mathrm{H}_{2} \mathrm{O}$ $\left(0.1 \mathrm{~g} \mathrm{~L}^{-1}\right), \mathrm{CaCl}_{2} \cdot 2 \mathrm{H}_{2} \mathrm{O}\left(0.004 \mathrm{~g} \mathrm{~L}^{-1}\right),\left(\mathrm{NH}_{4}\right)_{2} \mathrm{SO}_{4}$ (nitrogen source, $0.625 \mathrm{~g} \mathrm{~L}^{-1}$ in $\mathrm{FC}$ and $0.361 \mathrm{~g} \mathrm{~L}^{-1}$ in SC); $\mathrm{Na}_{2} \mathrm{HPO}_{4} \cdot 12 \mathrm{H}_{2} \mathrm{O}\left(1.6 \mathrm{~g} \mathrm{~L}^{-1}\right), \mathrm{KH}_{2} \mathrm{PO}_{4}(1.6$ $\left.\mathrm{g} \mathrm{L}^{-1}\right)$ and the main carbon source $\left(15 \mathrm{~g} \mathrm{~L}^{-1}\right)$. The $\mathrm{pH}$ of the media was adjusted to 7.0 with $\mathrm{NaOH}$ $\left(10 \mathrm{~mol} \mathrm{~L}^{-1}\right)$ or $\mathrm{HCl}\left(10 \mathrm{~mol} \mathrm{~L}^{-1}\right)$.

\section{Shaker flask cultivation}

Tests were executed in triplicate in $250-\mathrm{mL}$ flasks containing $50 \mathrm{~mL}$ of nutrient broth medium and $2 \mathrm{~mL}$ of pre-culture inoculum, which was incubated at $30^{\circ} \mathrm{C}$ in a shaking flask without baffles for $24 \mathrm{~h}$ (best cell concentration, $1011 \mathrm{UFC} \mathrm{mL}^{-1}$ ) at $150 \mathrm{rpm}$. FC cultivations were executed in flasks containing $80 \mathrm{~mL}$ nitrogen-non-limited mineral me- 
dium with addition of $10 \% \mathrm{v} / \mathrm{v}$ of the inoculum culture and incubated at $30{ }^{\circ} \mathrm{C}$ and $150 \mathrm{rpm}$ in orbital shaker for $24 \mathrm{~h}$. SCs were run in flasks containing $80 \mathrm{~mL}$ nitrogen-limited mineral medium with the addition of $10 \% \mathrm{v} / \mathrm{v}$ of $\mathrm{FC}$ and incubated at $35^{\circ} \mathrm{C}$ and $180 \mathrm{rpm}$ in orbital shaker for $72 \mathrm{~h}$.

\section{PHA recovery and separation}

Cell cultures were harvested by centrifugation at $15,700 \times \mathrm{g}$ for $30 \mathrm{~min}$ at $5{ }^{\circ} \mathrm{C}$ (HITACHI, model CR 22G), washed twice with distilled water, transferred into round bottom flasks $(50 \mathrm{~mL})$, and frozen at $-80{ }^{\circ} \mathrm{C}$ for subsequent lyophilization (LIOBRAS model L101) at $-42{ }^{\circ} \mathrm{C}$ for $24 \mathrm{~h}$. PHA extraction from the freeze-dried cells was performed using chloroform at $60{ }^{\circ} \mathrm{C}$ for $2 \mathrm{~h}$ with vigorous stirring on a magnetic stirrer plate with heating (model IKAHS 7) ${ }^{25}$. Biomass and PHA production (obtained after extraction) were calculated using a gravimetric method and expressed in $\mathrm{g} \mathrm{L}^{-1}$.

\section{PHA characterization}

Fourier transform infrared spectroscopy (FTIR)

PHA functional groups characterization was determined by FTIR spectroscopy (PerkinElmer Spectrum 100, Waltham, Massachusetts, USA) between the wave numbers of $4000 \mathrm{~cm}^{-1}$ and $400 \mathrm{~cm}^{-1}$ using a single-bounce attenuated total reflection (ATR) accessory with a Zinc selenide ( $\mathrm{ZnSe}$ ) crystal.

\section{Thermal characterization}

Thermogravimetric analysis (TGA) (PerkinElmer Model Pyris 1TGA Waltham, Massachusetts, USA) was performed to determine the initial degradation temperature $\left(T_{\text {onset }}\right)$ and the maximum decomposition temperature $\left(T_{\max }\right)$. Five milligrams of PHA were placed in a platinum tray (cross-sectional area of $2.47 \cdot 10^{-5} \mathrm{~m}^{2}$ ) and heated at the rate of 10 ${ }^{\circ} \mathrm{C} \min ^{-1}$ from $25{ }^{\circ} \mathrm{C}$ to $600{ }^{\circ} \mathrm{C}$ under a nitrogen

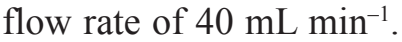

\section{X-ray diffraction analysis}

Crystallinity and crystal peaks of the PHA sample were measured by X-ray diffraction. The X-ray diffractograms of the samples were obtained on a SHIMADZU (XRD-6000, USA) with graphite-filtered $\mathrm{CuKa}$ radiation $(\lambda=1.5433 \AA)$ operated at 40 $\mathrm{kV}$ and $30 \mathrm{~mA}$ in the region from 5 to $80^{\circ}(2 \theta)$ at a rate of $2^{\circ} \mathrm{min}^{-1}$. The percentage of crystallinity was calculated from the diffracted intensity measured by XRD according to the Vonk's method ${ }^{26}$.
Determination of PHA molar mass distribution

Molar masses, expressed by the weight average molar mass $\left(M_{\mathrm{w}}\right)$, the number average molar mass $\left(M_{\mathrm{n}}\right)$ and the polydispersity index $\left(\mathrm{PDI}=M_{\mathrm{w}} / M_{\mathrm{n}}\right)$, were obtained by size-exclusion chromatography (SEC) according to Campos et al. ${ }^{25}$ and Ribeiro et al. ${ }^{27}$

High performance liquid chromatography (HPLC, PerkinElmer 200) with an autosampler and refractive index detector (PerkinElmer), a column Shodex KD $807(30 \mathrm{~cm} \times 78 \mathrm{~mm} \times 5 \mu \mathrm{m})$ with an exclusion volume of $2 \times 10^{8}$ and an oven temperature of $35^{\circ} \mathrm{C}$ were employed for separation. The polymer samples were dissolved in chloroform to a concentration of $7 \mathrm{mg} \mathrm{mL}^{-1}$. In the mobile phase, chloroform was employed at $1 \mathrm{~mL} \min ^{-1}$. A standard curve was created using polystyrene standards with a range size of 68-1,670,000 $\mathrm{g} \mathrm{mol}^{-1}$ (Polystyrene High Mw Standards Kit Polymer Standards Service, USA).

\section{PHA composition}

The composition of the hydroxyalkanoates was determined using gas chromatography-mass spectrometry (GC-MS; Clarus 500 PerkinElmer) with the TurboMass software version 4.5.0 and the NIST 98 spectra library. Approximately $0.04 \mathrm{~g}$ of the dry PHA was subjected to methanolysis based on the method published by Braunegg et al. ${ }^{28}$ with the modifications proposed by Brandl et al. ${ }^{29}$ Analysis conditions were established according to Campos et $a l{ }^{25}$ The hydroxyalkanoates were identified by comparison of retention time with poly(R)-3-hydroxybutyric acid (Sigma-Aldrich) as the control. The mass spectra were compared with the NIST 98 spectra library.

\section{Data treatment}

Data treatment was performed using the tools available in the software Statistica 8.0 (Statsoft Inc., Tulsa). Statistical significance was calculated by Tukey's test.

\section{Results and discussion}

\section{Substrate chemical composition and medium carbon nitrogen ratio}

Elaeis guineensis is a plant that has its origin in Africa and stands out for having high oil production per unit area, popularly known as oil palm or African oil palm, it is a monocotyledon species of the Arecales order that belongs to the subfamily Arecoideae $^{30}$. Oil palm Southeast Asia plantations cover over $107,000 \mathrm{~km}^{2}$, being a large-scale commer- 
cial tree crop with fundamental economic importance $^{31}$.

Table 1 presents the chemical composition determined for the crude palm oil used as sole carbon source in the bio-catalyzed submerged cultivations for PHA synthesis studied in this paper. It is possible to observe that the highest fractions in the oil are comprised of Palmitic (C16:0) and Oleic (C18:109) fatty acids. The substrate fatty acids composition is known to exert a major influence in PHA chain length and structure, since they may function as PHA copolymers ${ }^{32,33}$.

Crude palm oil fatty acids profile was comprised of $31.28 \%$ saturated fatty acids (Butyric [C4:0], Undecylic [C11:0], Lauric [C12:0], Myristic [C14:0], Palmitic [C16:0], Stearic [C18:0] and Arachidic [C20:0]), 54.92\% monounsaturated fatty ac-

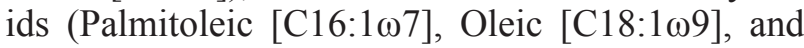
Gondoic [C20:1 $\omega 9]$ ), and $13.41 \%$ polyunsaturated

Table 1 - Fatty acid profile of the crude palm oil (Elaeis guineensis) used in the submerged cultivation of B. cepacia and C. necator strains for polymer production

\begin{tabular}{l|c}
\hline \multicolumn{1}{c|}{ Fatty acid } & Average (\%) \\
\hline $\mathrm{C} 4: 0$ & $0.23 \pm 0.03$ \\
$\mathrm{C} 11: 0$ & $0.05 \pm 0.01$ \\
$\mathrm{C} 12: 0$ & $0.10 \pm 0.09$ \\
$\mathrm{C} 14: 0$ & $0.33 \pm 0.05$ \\
$\mathrm{C} 16: 0$ & $26.44 \pm 0.25$ \\
$\mathrm{C} 16: 1 \omega 7$ & $0.13 \pm 0.02$ \\
$\mathrm{C} 18: 0$ & $3.65 \pm 0.09$ \\
$\mathrm{C} 18: 1 \omega 9 \mathrm{c}$ & $53.77 \pm 0.46$ \\
$\mathrm{C} 18: 1 \omega 9 \mathrm{t}$ & $0.73 \pm 0.02$ \\
$\mathrm{C} 18: 2 \omega 6 \mathrm{c}$ & $13.41 \pm 0.28$ \\
$\mathrm{C} 20: 0$ & $0.48 \pm 0.05$ \\
$\mathrm{C} 20: 1 \omega 9$ & $0.30 \pm 0.08$ \\
\hline
\end{tabular}

Table 2 - PHA and biomass production, and PHA extraction in fermentation of $15 \mathrm{~g} \mathrm{~L} \mathrm{~L}^{-1}$ of palm oil over 72 hours of incubation, $\mathrm{pH}$ of 7.0, and rotation of $150 \mathrm{rpm}$

\begin{tabular}{l|c|c|c}
\hline Microorganism & $\begin{array}{c}\text { PHA } \\
\left(\mathrm{g} \mathrm{L}^{-1}\right)\end{array}$ & $\begin{array}{c}\text { Biomass } \\
\left(\mathrm{g} \mathrm{L}^{-1}\right)\end{array}$ & $\begin{array}{c}\text { PHA } \\
\text { extraction } \\
(\%)\end{array}$ \\
\hline C. necator IPT 026 & $1.20 \pm 0.06^{\mathrm{b}}$ & $2.29 \pm 0.08^{\mathrm{a}}$ & 52.55 \\
C. necator IPT 027 & $1.45 \pm 0.16^{\mathrm{a}}$ & $2.41 \pm 0.14^{\mathrm{a}}$ & 60.03 \\
B. cepacia IPT 119 & $0.43 \pm 0.03^{\mathrm{c}}$ & $1.44 \pm 0.04^{\mathrm{c}}$ & 29.63 \\
B. cepacia IPT 400 & $0.10 \pm 0.05^{\mathrm{d}}$ & $0.45 \pm 0.09^{\mathrm{d}}$ & 22.96 \\
\hline
\end{tabular}

Averages followed by different letters, in the upper right, show differences between strains in the same column, determined by Tukey's test $(P<0.05)$. fatty acid (Linoleic [C18:2 $\omega 6])$. Although biomass composition varies significantly depending on a variety of factors, such as plant development stage, growth location, and climate conditions ${ }^{34}$, the substrate studied showed a similar composition to that reported by Mozzon et al. ${ }^{35}$, displaying a high percentage of unsaturated fatty acids.

For fermentation, the cultivation medium (SC) was supplemented with a limiting $\left(\mathrm{NH}_{4}\right)_{2} \mathrm{SO}_{4}$ supply to obtain a carbon-to-nitrogen ratio $(\mathrm{C}: \mathrm{N})$ approximately equal to $114: 1$. This value is within the C:N range documented in literature for PHA production using the nitrogen limitation approach. Reported C:N values range from $20: 1$ to $180: 1$, depending largely on the bacterial strain used for bioconver$\operatorname{sion}^{36,37,38}$.

\section{Palm oil bioconversion}

The effect of Burkholderia cepacia IPT 400 and IPT 119, and Cupriavidus necator IPT 026 and IPT 027, for PHA production was tested in submerged cultivations using crude palm oil as substrate in limiting nitrogen conditions, Table 2. Microorganism and substrate are variables of great importance in PHA bioconversion and their combined influence can largely influence the polymer production sustainability .

Thus, it was inferred that, regarding polymer synthesis, $C$. necator IPT 027 presented the highest PHA performance, $1.45 \mathrm{~g} \mathrm{~L}^{-1}$ (Table 2). In general, $C$. necator strains presented a better polymer synthesis activity compared to B. cepacia, with an average production 5 times higher. $C$. necator bacteria also presented the best biomass growth; these data reveal better adaptation of these strains to the palm oil substrate offered than that observed for $B$. серacia.

Polyesters percentage extraction were significantly lower for B. cepacia bacteria, revealing that the cultivation conditions established triggered growth phase in a more effective manner than polymer accumulation (Table 2). This result suggests revaluation of the nitrogen limitation strategy (famine period) used for the mentioned strains in this study, indicating that a more severe nitrogen restriction must be set, since the limitation of this nutrient generates a cellular trauma that leads to PHA accumulation $^{39}$.

Variance analysis (ANOVA) showed that the different microorganisms studied presented greater impact on biomass production $(F=273.1, p<0.0001)$ than on PHA synthesis $(F=155.5, p<0.0001)$. This phenomenon reflects high variation in the strains development in the same medium and cultivation conditions, revealing very distinct growth behaviors. 


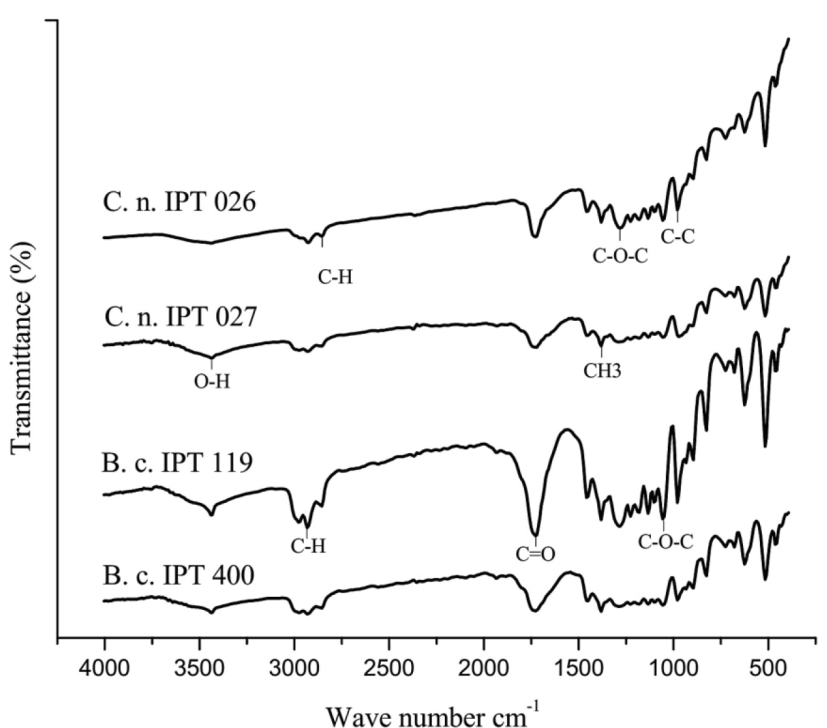

Fig. 1 - FTIR spectra of PHA produced by C. necator and $B$. cepacia strains in submerged cultivation with crude palm oil

Applying the same concentration of oil used in the present study, Wong et al. ${ }^{24}$ described $2.60 \mathrm{~g} \mathrm{~L}^{-1}$ of PHA production by recombinant $C$. necator Re2160/pCB113 with crude palm kernel oil and $3.30 \mathrm{~g} \mathrm{~L}^{-1}$ with coconut oil (by the same strain). Altaee et al. ${ }^{40}$ reported $0.54 \mathrm{~g} \mathrm{~L}^{-1}$ of PHA in their culture medium using palm oil as substrate and Rhodococcus equi as biocatalyst. Mozejko and Ciesielski ${ }^{41}$ published $2.24 \mathrm{~g} \mathrm{~L}^{-1}$ PHA production with saponified waste palm oil and Pseudomonas sp. G101.

These data evidence and confirm high dependence of PHA production on the microorganism used for the bioconversion and the substrate offered, validating and encouraging the investigations on performance of new microorganisms and cheap carbon sources towards the sustainability of PHA production chain.

\section{Biopolymers characterization}

All biopolymers produced by $C$. necator and $B$. cepacia strains in submerged cultivations with crude palm oil were submitted to thermal, chemical and physical characterizations in order to evaluate the properties associated with their natural atomic structures and their capacity to attain standards that would endorse their commercial application.

The polymers functional groups characterization, presented in Fig. 1, was completed by spectroscopy in the infrared spectra (FTIR). All samples scanned showed the characteristic bands documented in the scientific literature related to PHAs structure, confirming the production of these polyesters.

The transmittance observed at $1728 \mathrm{~cm}^{-1}$ is associated with the axial deformation of $\mathrm{C}=\mathrm{O}$ carbonyl group ${ }^{42}$. The $\mathrm{C}-\mathrm{H}$ carbon-hydrogen bond stretching of $\mathrm{CH}_{3}$ and $\mathrm{CH}_{2}$ groups were present at the wave numbers $2931 \mathrm{~cm}^{-1}$ and $2854 \mathrm{~cm}^{-1}$, in this order $^{42,43}$.

Infrared transmittance at $3440 \mathrm{~cm}^{-1}$ was assigned to the hydroxyl group of the polymer chain ${ }^{45}$. The vibration band of the carbonyl of the ester group $(\mathrm{C}-\mathrm{C})$ is noted at $972 \mathrm{~cm}^{-1}{ }^{45}$.

The bands $1048 \mathrm{~cm}^{-1}$ and $1288 \mathrm{~cm}^{-1}$ are associated, correspondingly, to the asymmetric and the symmetric stretching vibration of the $\mathrm{C}-\mathrm{O}-\mathrm{C}$ group ${ }^{46}$. Wagging $\mathrm{CH}_{3}$ is observed at the wave number $1381 \mathrm{~cm}^{-1} 45$.

In Fig. 2, it is possible to see the chromatograms obtained by gas chromatography-mass spectrometry of the PHA samples produced by all the strains assessed in this study to determine the polymers monomeric composition, displayed in Table 3. Mass spectra of each peak were compared against NIST library for polymeric units identification.

Identified was the presence of five different monomeric units composing the structure of all copolymers produced in this study (Table 3). All strains evaluated produced polymers with major presence of hydroxyhexadecanoate and hydroxy-9octadecenoate. It is important to note that the major fractions of fatty acids in the palm oil substrate used in this study were composed of 16 and 18 carbons

Table 3 -Monomeric profile of the PHAs produced by C. necator and B. cepacia bacteria, using crude palm oil as substrate, obtained by gas chromatography-mass spectrometry in the NIST library

\begin{tabular}{c|l|c|c|c|c}
\hline \multirow{2}{*}{$\begin{array}{c}\text { Retention time } \\
(\mathrm{min})\end{array}$} & Monomer & \multicolumn{4}{|c}{ Composition of polymer sample (\%) } \\
\cline { 3 - 7 } & & IPT 026 & IPT 027 & IPT 119 & IPT 400 \\
\hline 6.27 & Hydroxytetradecanoate & 1.86 & 4.69 & 3.61 & 4.92 \\
7.78 & Hydroxyhexadecanoate & 47.51 & 53.15 & 50.34 & 41.43 \\
9.75 & Hydroxy-9,12-octadecadienoate & 5.75 & 5.47 & 5.76 & 8.69 \\
9.93 & Hydroxy-9-octadecenoate & 29.61 & 22.07 & 14.91 & 26.82 \\
10.38 & Hydroxyoctadecanoate & 7.58 & 7.70 & 8.50 & 5.76 \\
- & NI & 7.69 & 6.92 & 16.88 & 12.38 \\
\hline
\end{tabular}

$\mathrm{NI}=$ Not Identified 

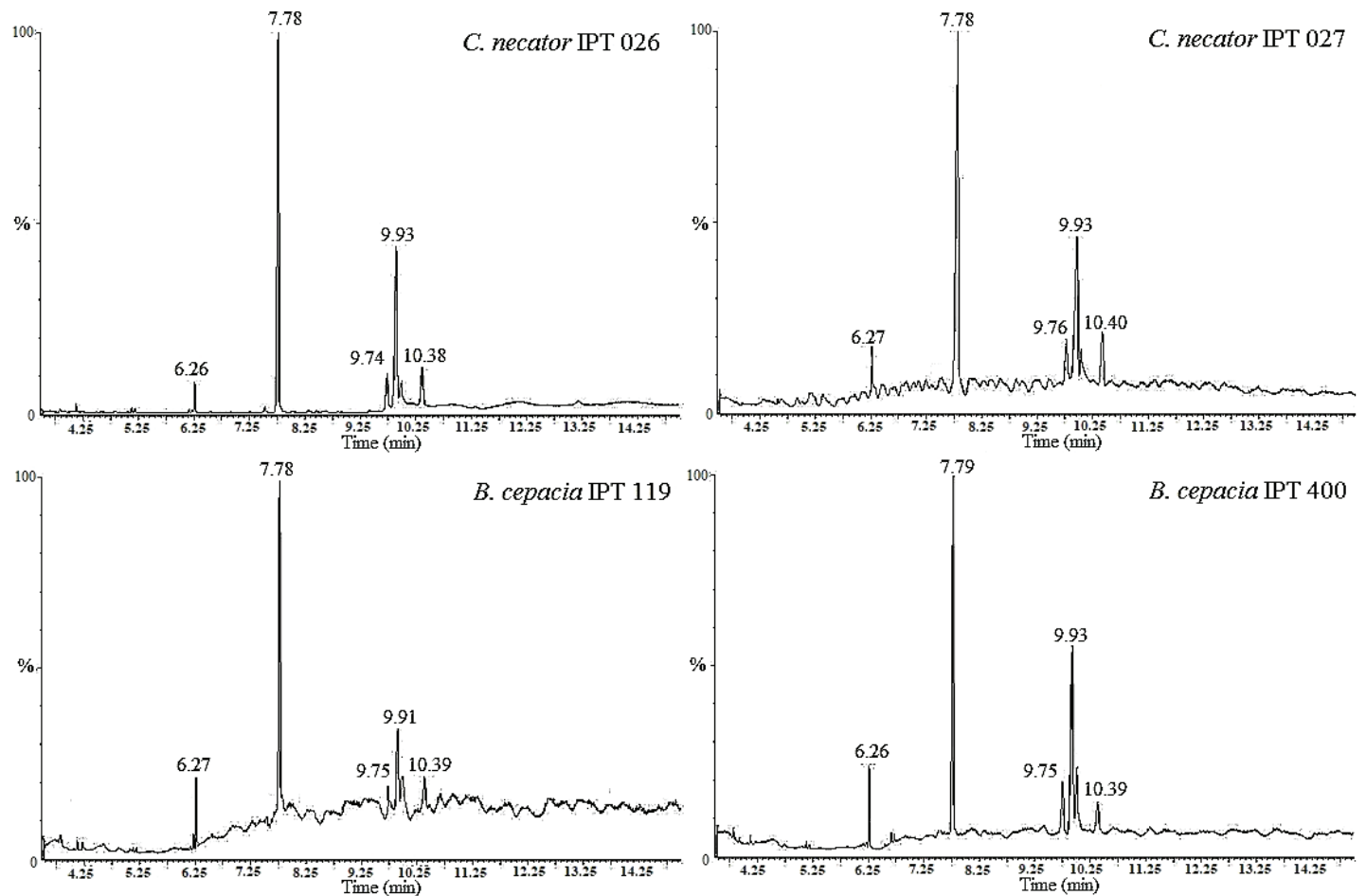

Fig. 2 - Chromatograms obtained by gas chromatography-mass spectrometry of PHA produced by C. necator and B. cepacia strains in submerged cultivation with crude palm oil

fatty acids (Table 1). These results indicate that the substrate offered for $C$. necator and B. cepacia played a key role in the PHAs compositions.

In concordance with the data exposed, Thompson and $\mathrm{He}^{32}$, and Srivastava and Tripathi ${ }^{33}$ reported that the presence of fatty acids in the fermentative medium is known to greatly influence PHA chain length and structure. It has been published that microorganisms use short, medium, and long chains of fatty acids as carbon sources to obtain polyunsaturated fatty acids, which may function as PHA copolymers.

X-ray diffractograms of the PHAs produced with $C$. necator and B. cepacia strains are displayed in Fig. 3, along with their crystallinity index $\left(\mathrm{I}_{\mathrm{c}}\right)$, which is an indication of the percentage amount of polymer chains organized in the form of crystals in the material structure.

Crystallinity is an important property that largely influences polymer mechanical characteristics, such as yield stress, elastic modulus, and impact resistance. This parameter is also crucial for polymer processing and its desirable value must not be much higher than $50 \%$, or else brittleness and rigidity starts to cause complications related to the material applications ${ }^{47,48,49}$.

It is possible to observe (Fig. 3) the diffraction peaks at $2 \theta$ for all polymer samples assessed, and their intensity variations due to the different producer microorganisms from which they originated. De- spite that, all PHA presented peaks in $13.56^{\circ}$, $16.96^{\circ}, 21.89^{\circ}$ and $25.52^{\circ}$, typically associated with a semi-crystalline arrangement in polyesters ${ }^{43}$.

$I_{c}$ of the PHAs studied ranged from $48.47 \%$ (C. necator IPT 026) to $27.80 \%$ (B. cepacia IPT $400)$, demonstrating that the microorganism strain had significant impact in the polyesters structure arrangement. In general, the biomaterials produced by C. necator bacteria exhibited crystallinity indexes

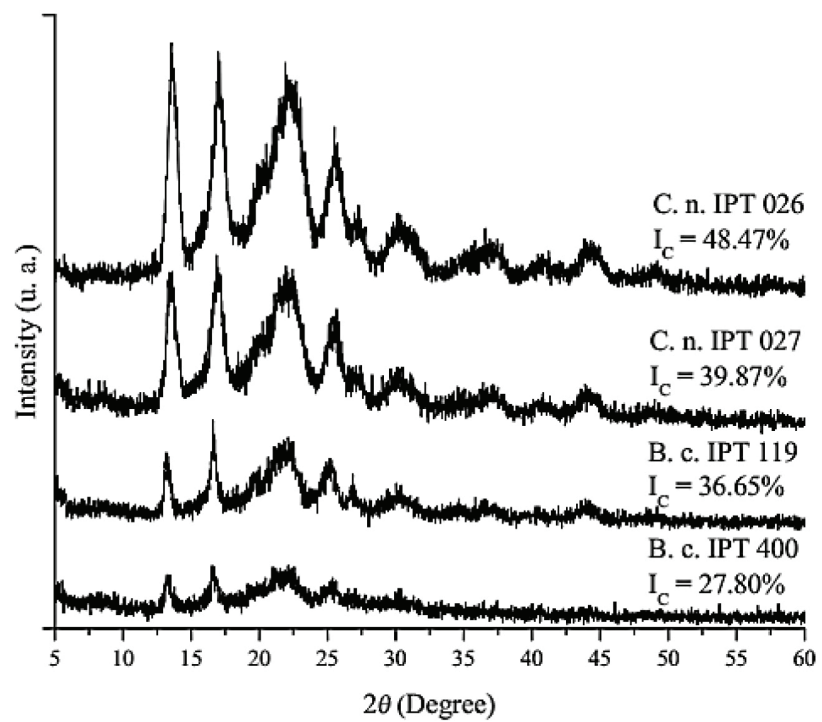

Fig. 3 - X-ray diffractograms of PHA produced by $C$. necator and B. cepacia strains in submerged cultivation with crude palm oil 

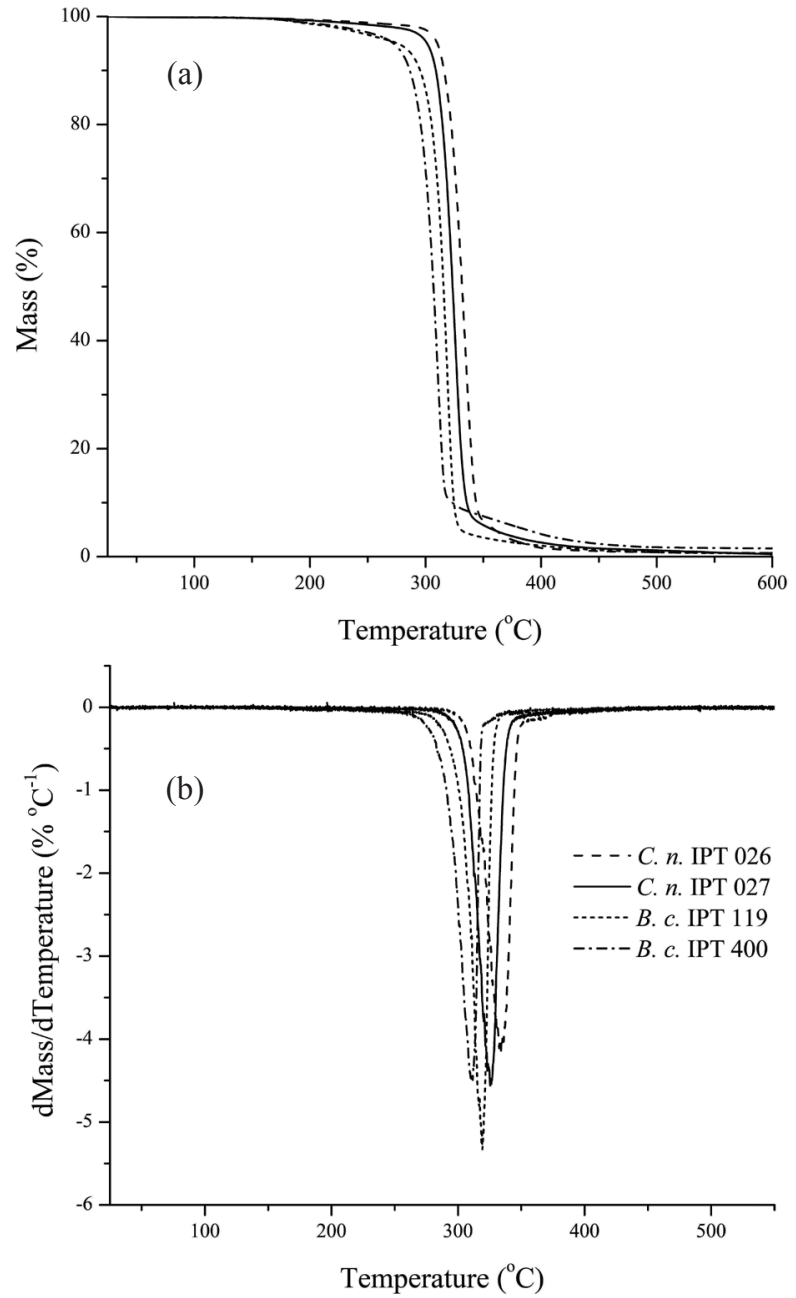

Fig. 4 - TGAs (a) and DTGs (b) of crude palm oil and PHAs produced by $C$. necator and B. cepacia strains in submerged cultivation

superior to those produced by B. cepacia, however, all polymers synthesized in this study showed predominant amorphous phase. This indicates good performance concerning their structural morphology in regard of the biosynthesis conditions set and the biocatalysts used ${ }^{48,49}$.

The processing of biopolymers is also challenged by their often low thermal stability, since it restricts the temperatures and time by which these materials can be processed ${ }^{50,51}$. PHAs thermal behaviors are displayed in the thermogravimetric curves (TGA) and its associated derivatives (DTGA) in Fig. 4. TGA curves depict the mass variation of the polymer samples as a function of temperature increase, which is related to the loss of volatile components. DTGA curves, first derivatives of the TGA, show the rate of thermal decomposition of the sample.

Thermal degradation of all polymers studied occurred in only one mass loss event (Fig. 4), indicating the presence of no impurities remaining from
Table 4 -Initial degradation ( $T$ ) and maximum decomposition temperatures $\left(T_{\text {mox }}\right)$, along with total weight loss of PHAs produced by $C$. necator and B. cepacia strains using crude palm oil

\begin{tabular}{l|c|c|c}
\hline $\begin{array}{c}\text { Microorganism } \\
\text { strain }\end{array}$ & $T_{\text {onset }}\left({ }^{\circ} \mathrm{C}\right)$ & $T_{\max }\left({ }^{\circ} \mathrm{C}\right)$ & $\begin{array}{c}\text { Total mass loss } \\
(\%)\end{array}$ \\
\hline C. necator IPT 026 & 311.86 & 334.42 & 99.35 \\
C. necator IPT 027 & 305.38 & 325.92 & 99.61 \\
B. cepacia IPT 119 & 291.29 & 319.12 & 99.34 \\
B. cepacia IPT 400 & 283.70 & 310.76 & 98.55 \\
\hline
\end{tabular}

the extraction and separation processes on those materials ${ }^{36}$. Initial degradation temperatures $\left(T_{\text {onset }}\right)$ and maximum decomposition temperatures $\left(T_{\text {max }}\right)$ of the thermogravimetric events obtained from TGA/ DTGA curves for the PHAs produced from crude palm oil are presented in Table 4 .

All polymers produced demonstrated initial thermal degradation above $283{ }^{\circ} \mathrm{C}$, with emphasis on the PHA synthetized by $C$. necator IPT 026 , which exhibited the best thermal stability with an initial degradation temperature of $311.86{ }^{\circ} \mathrm{C}$, a maximum decomposition temperature of $334.42{ }^{\circ} \mathrm{C}$ and a total weight loss of $99.35 \%$. Similarly to what was found for the last strain, Ribeiro et al. ${ }^{52}$ reported a PHA with initial degradation temperature of $316.7{ }^{\circ} \mathrm{C}$ in the bioconversion (Burkholderia cepacia IPT 438) of glycerol, and Campos et al. ${ }^{25}$ described a $T_{\text {onset }}$ of $306.8{ }^{\circ} \mathrm{C}$ for PHA produced by $C$. necator IPT 026 in consumption of crude glycerol.

The performances of all biopolymers synthesized in the present study were substantially superior to those found in PHAs produced by Lysinibacillus sp. $\left(T_{\text {onset }}=114.7^{\circ} \mathrm{C}\right)$, reported by Mohapatra et al.$^{53}$, Pseudomonas pseudoflava $\left(T_{\text {onset }}=140-170{ }^{\circ} \mathrm{C}\right)$, reported by Reddy et al. ${ }^{1}$ and Bacillus megaterium $\left(T_{\text {onset }}=192.23-281.83{ }^{\circ} \mathrm{C}\right)$, published by Ribeiro et al. ${ }^{27}$

Observed was a linear correlation between initial temperature of degradation and crystallinity index for the polymers evaluated $\left(R^{2}=0.91\right)$. $T_{\text {onset }}$ increases with the increase in $\mathrm{I}_{\mathrm{c}}$ according to Eq. (2).

$$
T_{\text {onset }}=1.434 \mathrm{I}_{\mathrm{c}}+243.28 \quad R^{2}=0.9071
$$

This correlation is reasonable and probably due to the ordered conformation of crystals in the polymer structure, maintained/linked by a group of chemical bonds stronger than those observed for amorphous conformations. Thus, an elevated amount of crystallinity would offer high resistance to thermal degradation once an elevated number of chemical bonds would have to be broken for the polymer to decompose ${ }^{54}$. 


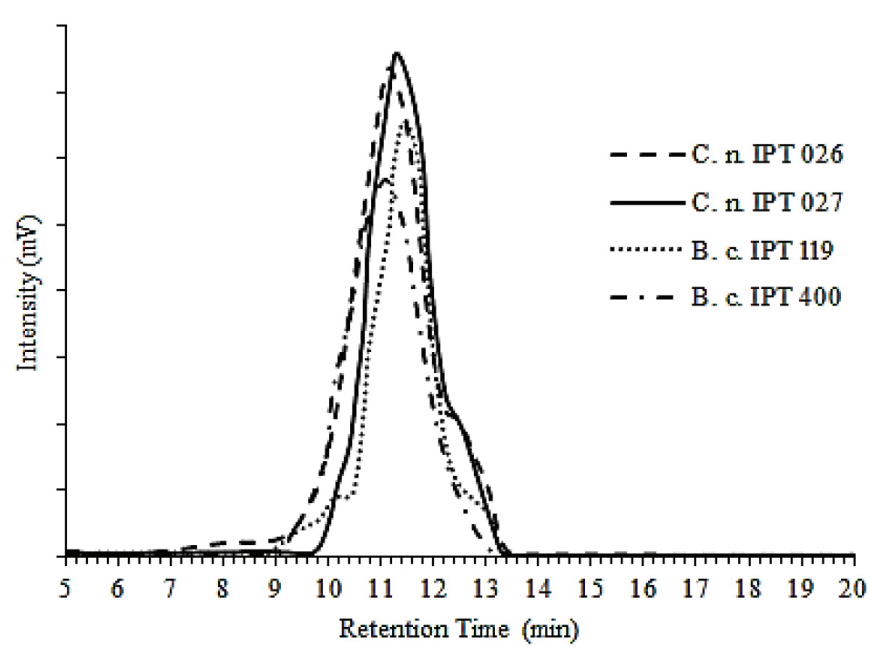

Fig. 5 - HPLC-RI chromatograms of PHAs produced by the C. necator and B. cepacia strains from crude palm oil in submerged cultivations

Fig. 5 displays the HPLC-RI chromatograms of the PHAs separation. Size-exclusion chromatography was used to obtain maximum, average and minimum molecular mass $\left(M_{\mathrm{w}}\right)$, number average molecular mass $\left(M_{\mathrm{n}}\right)$, and polydispersity (PDI) of the PHAs produced in this study, Table 5. A calibration curve was built using standard polystyrene with different values of $M_{\mathrm{w}}$ as a function of column retention time $(t)$. This curve was used to calculate the samples $M_{\mathrm{w},}$ and is presented in Eq. (3).

$$
\log \left(M_{\mathrm{w}}\right)=-0.8364 t+14.831 \quad R^{2}=0.9917
$$

The biocatalyst variable played an important role in the weight average molecular mass of the copolymers produced, since this response parameter varied largely depending on the bacterial strain. The highest $(389.296 \mathrm{kDa})$ and the lowest $(173.781$ $\mathrm{kDa}$ ) weight average molecular mass was observed for the PHAs produced by B. cepacia strains, IPT 400 and IPT 119, respectively.

Gumel et al. ${ }^{55}$, studying the substrate effect in PHA production from Pseudomonas putida, found weight average molecular masses ranging from 55 to $77 \mathrm{kDa}$, while Ribeiro et al. ${ }^{27}$, using different

Table 5 - Molar mass of PHA produced by the C. necator and B. cepacia strains from crude palm oil

\begin{tabular}{l|ccc|c|c|c}
\hline \multirow{2}{*}{ Microorganism } & \multicolumn{4}{|c|}{$M_{\mathrm{w}}(\mathrm{kDa})$} & $M_{\mathrm{n}}$ & PDI \\
\cline { 2 - 6 }$(\mathrm{kDa})$ & Minimum & Medium & Maximum & & \\
\hline C. necator IPT 026 & 5.61 & 321.28 & 10650.94 & 130.86 & 2.46 \\
C. necator IPT 027 & 4.81 & 240.87 & 3553.37 & 141.83 & 1.70 \\
B. cepacia IPT 119 & 5.09 & 173.78 & 9673.15 & 104.34 & 1.67 \\
B. cepacia IPT 400 & 8.57 & 389.30 & 13164.13 & 190.71 & 2.04 \\
\hline
\end{tabular}

crude glycerol sources for PHA production, reported a range of 1400 to $3740 \mathrm{kDa}$, in submerged cultivations of Bacillus megaterium. Pan et al. ${ }^{7}$ reported $M_{\mathrm{w}}$ of $450.8 \mathrm{kDa}$ by Burkholderia cepacia using a detoxified sugar maple hemicellulosic hydrolysate, and Campos et al. ${ }^{25}$ described a range of 510 $\mathrm{kDa}$ to $780 \mathrm{kDa}$, by Cupriavidus necator using crude glycerol. This illustrates the great variety of molecular masses reported in literature in response to the use of different biocatalysts, substrates and cultivation conditions.

Regarding polymer polydispersity (PDI) (Table 5), C. necator and B. cepacia bacteria produced materials with good homogeneity of molecular masses, representing good bacterial biosynthesis consistency. The PDI values identified for the polymeric samples in this study ranged from 1.67 to 2.46 , revealing the production of materials far more uniform than those reported by Sang-Hyeop et al. ${ }^{56}$ in their investigations with PHA production from wastewater sludge (PDI = 3.44), and Gahlawat and Soni ${ }^{44}$, with their $\mathrm{P}(3 \mathrm{HB}-\mathrm{co}-3 \mathrm{HV})$ copolymer production by $C$. necator DSM 545 (PDI = 4.3) using waste glycerol.

\section{Conclusions}

The bacterial strains investigated were able to use crude palm oil as substrate to synthesize novel PHAs mostly constituted of long side chain monomers $-\mathrm{C} 16$ and $\mathrm{C} 18$, which is a rare feature in the polymers field. All copolymers produced presented variable monomeric composition and molar masses, with predominant amorphous molecular arrangements, high thermal stability, and low polydispersity. $C$. necator exhibited the highest performance in biosynthesis. $C$. necator and $B$. cepacia bacterial strains presented great effects in PHAs production and properties, confirming the importance of the biocatalysts variable in the bioprocess. Medium composition and fermentation conditions can be optimized to maximize biomass and biopolymer production. Additionally, the understanding of biochemical and cellular mechanisms of PHA production and accumulation, associated with new techniques of polymer extraction can provide valuable insights to overcome the hurdles in the utilization of these bioplastics.

\section{ACKNOWLEDGEMENTS}

The authors wish to thank the financial support from National Council of Research-CNPq (DT 400170/2014-5, INCT MIDAS 465594/2014-0) and from FAPESB (BOL0564/2016 scholarship granted to Plínio R. Rodrigues). 


\section{References}

1. Reddy, M. V., Mawatari, Y., Onodera, R., Nakamura, Y., Yajima, Y., Chang, Y. C., Polyhydroxyalkanoates production from synthetic waste using Pseudomonas pseudoflava: Polyhydroxyalkanoate synthase enzyme activity analysis from $P$. pseudoflava and $P$. palleronii, Bioresour. Technol. 234 (2017) 99.

doi: https://doi.org/10.1016/j.biortech.2017.03.008

2. Koller, M., Salerno, A., Dias, M., Reiterer, A., Braunegg, $G$., Modern biotechnological polymer synthesis: A review, Food Technol. Biotechnol. 48 (2010) 255.

3. Kaur, G., Roy, I., Strategies for large-scale production of polyhydroxyalkanoates, Chem. Biochem. Eng. Q. 29 (2015) 157. doi: https://doi.org/10.15255/CABEQ.2014.2255

4. Huang, L., Chen, Z., Wen, Q., Lee, D. J., Enhanced polyhydroxyalkanoate production by mixed microbial culture with extended cultivation strategy, Bioresour. Technol. 241 (2017) 802 .

doi: https://doi.org/10.1016/j.biortech.2017.05.192

5. Chen, Z., Guo, Z., Wen, Q., Huang, L., Bakke, R., Du, M., Modeling polyhydroxyalkanoate (PHA) production in a newly developed aerobic dynamic discharge (ADD) culture enrichment process, Chem. Eng. J. 298 (2016) 36. doi: https://doi.org/10.1016/j.cej.2016.03.133

6. Venkata, M. S., Venkateswar, R. M., Optimization of critical factors to enhance polyhydroxyalkanoates (PHA) synthesis by mixed culture using Taguchi design of experimental methodology, Bioresour. Technol. 128 (2013) 409. doi: https://doi.org/10.1016/j.biortech.2012.10.037

7. Pan, W., Perrotta, J. A., Stipanovic, A. J., Nomura, C. T., Nakas, J. P. J., Production of polyhydroxyalkanoates by Burkholderia cepacia ATCC 17759 using a detoxified sugar maple hemicellulosic hydrolysate, Ind. Microbiol. Biotechnol. 39 (2012) 459. doi: https://doi.org/10.1007/s10295-011-1040-6

8. Colombo B., Pepè, S. T., Reis, M., Scaglia, B., Adani, F., Polyhydroxyalkanoates (PHAs) production from fermented cheese whey by using a mixed microbial culture, Bioresour. Technol. 218 (2016) 692. doi: https://doi.org/10.1016/j.biortech.2016.07.024

9. Koller, M., Maršálek, L., Dias, M. M. S., Braunegg, G., Producing microbial polyhydroxyalkanoate (PHA) biopolyesters in a sustainable manner, New Biotechnol. 37 (2017) 24. doi: https://doi.org/10.1016/j.nbt.2016.05.001

10. Povolo, S., Basaglia, M., Fontana, F., Morelli, A., Casella, S., Poly(hydroxyalkanoate) Production by Cupriavidus necator from fatty waste can be enhanced by phaZ1 inactivation, Chem. Biochem. Eng. Q. 29 (2015) 67.

doi: https://doi.org/10.15255/CABEQ.2014.2248

11. Hassan, M. A., Yee, L. N., Yee, P. L., Ariffin, H., Raha, A. R., Shirai, Y., Sudesh, K., Sustainable production of polyhydroxyalkanoates from renewable oil-palm biomass, Biomass Bioenergy 50 (2013) 1. doi: https://doi.org/10.1016/j.biombioe.2012.10.014

12. Wong, Y. M., Brigham, C. J., Rha, C. K., Sinskey, A. J., Sudesh, K., Biosynthesis and characterization of polyhydroxyalkanoate containing high 3-hydroxyhexanoate monomer fraction from crude palm kernel oil by recombinant Cupriavidus necator, Bioresour. Technol. 121 (2012) 320. doi: https://doi.org/10.1016/j.biortech.2012.07.015

13. Budde, C. F., Riedel, S. L., Willis, L. B., Rha, C., Sinskey, A. $J$. , Production of poly(3-hydroxybutyrate-co-3-hydroxyhexanoate) from plant oil by engineered Ralstonia eutropha strains, Appl. Environ. Microbiol. 77 (2011) 2847. doi: https://doi.org/10.1128/AEM.02429-10

14. Walsh, M., O'Connor, K., Babu, R., Woods, T., Kenny, S., Plant oils and products of their hydrolysis as substrates for polyhydroxyalkanoate synthesis, Chem. Biochem. Eng. Q. 29 (2015) 123. doi: https://doi.org/10.15255/CABEQ.2014.2252

15. Akiyama, M., Tsuge, T., Doi, Y., Environmental life cycle comparison of polyhydroxyalkanoates produced from renewable carbon resources by bacterial fermentation, Polym. Degrad. Stab. 80 (2003) 183. doi: https://doi.org/10.1016/S0141-3910(02)00400-7

16. Tsuge, T., Taguchi, K., Seiichi, T., Doi, Y., Molecular characterization and properties of (R)-specific enoyl-CoA hydratases from Pseudomonas aeruginosa: metabolic tools for synthesis of polyhydroxyalkanoates via fatty acid beta-oxidation, Int. J. Biol. Macromol. 31 (2003) 195. doi: https://doi.org/10.1016/S0141-8130(02)00082-X

17. Chen, G. Q., Hajnal, I., Wu, H., Lv, L, Ye, J., Engineering biosynthesis mechanisms for diversifying polyhydroxyalkanoates, Trends Biotechnol. 33 (2015) 565. doi: https://doi.org/10.1016/j.tibtech.2015.07.007

18. Hoffmann, M. P., Vera, A. C., Wijk, M. T., Giller, K. E., Oberthür, T., Donough, C., Whitbread, A. M., Simulating potential growth and yield of oil palm (Elaeis guineensis) with PALMSIM: Model description, evaluation and application, Agric. Sys. 131 (2014) 1. doi: https://doi.org/10.1016/j.agsy.2014.07.006

19. Khatun, R., Rezaa, M. I. H., Moniruzzamanb, M., Yaakob, $Z$., Sustainable oil palm industry: The possibilities, Renew. Sust. Energ. Rev. 76 (2017) 608. doi: https://doi.org/10.1016/j.rser.2017.03.077

20. Yasin, M. H. M., Mamat, R., Najafi, G., Ali, O. M., Yusop, A. F., Ali, M. H., Potentials of palm oil as new feedstock oil for a global alternative fuel: A review, Renew. Sust. Energ. Rev. 79 (2017) 1034. doi: https://doi.org/10.1016/j.rser.2017.05.186

21. Nelson, D. W., Sommers, L. E., Total carbon, organic carbon, and organic matter, in Page, A. L., Miller, R. H., Keeney, D. R. (Eds.), Methods of soil analysis. Part 2. Chemical and microbiological properties, American Society of Agronomy, Madison, 1982, pp 539-577.

22. Joseph, J. D., Ackman, R. G., Capillary column gas chromatographic method for analysis of encapsulated fish oils and fish oil ethyl esters: Collaborative study, J. AOAC Int. 75 (1992) 488.

23. Nascimento, I. A., Marques, S. S. I., Cabanelas, I. T. D., Pereira, S. A., Druzian, J. I., Screening microalgae strains for biodiesel production: lipid productivity and estimation of fuel quality based on fatty acids profiles as selective criteria, Bioenergy Res. 6 (2013) 1. doi: https://doi.org/10.1007/s12155-012-9222-2

24. Wang, B., Sharma-Shivappa, R. R., Olson, J. W., Khan, S. A., Production of polyhydroxybutyrate (PHB) by Alcaligenes latus using sugarbeet juice, Ind. Crops Prod. 43 (2013) 802. doi: https://doi.org/10.1016/j.indcrop.2012.08.011

25. Campos, M. I., Figueiredo, T. V. B., Sousa, L. S., Druzian, $J$. I., The influence of crude glycerin and nitrogen concentrations on the production of PHA by Cupriavidus necator using a response surface methodology and its characterizations, Ind. Crops Prod. 52 (2014) 338. doi: https://doi.org/10.1016/j.indcrop.2013.11.008

26. Vonk, C. G., Computerization of Ruland's X-ray method for determination of the crystallinity in polymers, J. Appl. Cryst. 6 (1973) 148. doi: https://doi.org/10.1107/S0021889873008332

27. Ribeiro, P. L. L., Silva, A. C. M. S., Filho, J. A. M., Druzian, $J$. I., Impact of different by-products from the biodiesel industry and bacterial strains on the production, composition, and properties of novel polyhydroxyalkanoates containing achiral building blocks, Ind. Crops Prod. 69 (2015) 212. doi: https://doi.org/10.1016/j.indcrop.2015.02.035 
28. Braunegg, G., Sonnleitner, B. E., Lafferty, R. M., A rapid gas chromatographic method for the determination of poly- $\beta$-hydroxybutyric acid in microbial biomass, Eur. J. Appl. Microbiol. Biotechnol. 6 (1978) 29. doi: https://doi.org/10.1007/BF00500854

29. Brandl, H., Gross, R. A., Lenz, R. W., Fuller, R. C., Pseudomonas oleovorans as a source of poly( $\beta$-hydroxyalkanoates) for potential applications as biodegradable polyesters, Appl. Environ. Microbiol. 54 (1988) 1977.

30. Dransfield, J., Uhl, N. W., Asmussen, C. B., Baker, W. J., Harley, M. M., Lewis, C. E., A new phylogenetic classification of the Palm Family, Arecaceae, Kew Bull. 60 (2005) 559.

31. Carr, M. K. V., The water relations and irrigation requirements of oil palm (Elaeis guineensis), Exp. Agric. 47 (2011) 629. doi: https://doi.org/10.1017/S0014479711000494

32. Thompson, J. C., He, B. B., Characterization of crude glycerol from biodiesel production from multiple feedstocks, Appl. Eng. Agric. 22 (2006) 261. doi: https://doi.org/10.13031/2013.20272

33. Srivastava, S. K., Tripathi, A. D., Effect of saturated and unsaturated fatty acid supplementation on bio-plastic production under submerged fermentation, Biotech. 3 (2013) 389. doi: https://doi.org/10.1007/s13205-012-0110-4

34. Zeng, Y., Liu, T., Zhou, X., Sun, Q., Han, Z., Liu, K., Effects of climate change on plant composition and diversity in the Gurbantünggüt Desert of northwestern China, Ecol. Res. 31 (2016) 427. doi: https://doi.org/10.1007/s11284-016-1352-0

35. Mozzon, M., Pacetti, D., Lucci, P., Balzano, M., Frega, N. $G$., Crude palm oil from interspecific hybrid Elaeis oleifera Elaeis guineensis: Fatty acid regiodistribution and molecular species of glycerides, Food Chem. 141 (2013) 245. doi: https://doi.org/10.1016/j.foodchem.2013.03.016

36. González-García, Y., Meza, J. C. C., Reynoso, O. G., López, $J$. A. C., Síntesis y biodegradación de polihidroxialcanoatos: Plásticos de origen microbiana, Rev. Int. Contam. Ambie. 29 (2013) 77.

37. Kumar, M. S., Mudliar, S. N., Reddy, K. M. K., Chakrabarti, $T$., Production of biodegradable plastics from activated sludge generated from a food processing industrial wastewater treatment plant, Bioresour. Technol. 95 (2004) 327. doi: https://doi.org/10.1016/j.biortech.2004.02.019

38. Wen, Q., Chen, Z., Tian, T., Chen, W., Effects of phosphorus and nitrogen limitation on PHA production in activated sludge, J. Environ. Sci. 22 (2010) 1602. doi: https://doi.org/10.1016/S1001-0742(09)60295-3

39. Madison, L. L., Huisman, G. W., Metabolic engineering of poly(3-hydroxyalkanoates): from DNA to plastic, Microbiol. Mol. Biol. Rev. 63 (1999) 21.

40. Altaee, N., Fahdil, A., Yousif, E., Sudesh, K., Recovery and subsequent characterization of polyhydroxybutyrate from Rhodococcus equi cells grown on crude palm kernel oil, J. Taibah. Univ. Sci. 10 (2016) 543. doi: https://doi.org/10.1016/j.jtusci.2015.09.003

41. Możejko, J., Ciesielski, S., Saponified waste palm oil as an attractive renewable resource for mcl-polyhydroxyalkanoate synthesis, J. Biosci. Bioeng. 116 (2013) 485. doi: https://doi.org/10.1016/j.jbiosc.2013.04.014

42. Hong, K., Sun, S., Tian, W., Chen, G. Q., Huang, W., A rapid method for detecting bacterial polyhydroxyalkanoates in intact cells by Fourier transform infrared spectroscopy, Appl. Microbiol. Biotechnol. 51 (1999) 523. doi: https://doi.org/10.1007/s002530051427

43. Barud, H. S., Souza, J. L., Santos, D. B., Crespi, M. S., Ribeiro, C. A., Messaddeq, Y., Ribeiro, S. J. L., Bacterial cellulose/poly(3-hydroxybutyrate) composite membranes, Carbohydr. Polym. 83 (2011) 1279.

doi: https://doi.org/10.1016/j.carbpol.2010.09.049
44. Gahlawat, G., Soni, S. K., Valorization of waste glycerol for the production of poly (3-hydroxybutyrate) and poly (3-hydroxybutyrate-co-3-hydroxyvalerate) copolymer by Cupriavidus necator and extraction in a sustainable manner, Bioresour. Technol. 243 (2017) 492. doi: https://doi.org/10.1016/j.biortech.2017.06.139

45. Xu, J., Guo, B. H., Yang, R., Wu, Q., Chen, G. Q., Zhang, Z. $M$., In situ FTIR study on melting and crystallization of polyhydroxyalkanoates, Polymer. 43 (2002) 6893. doi: https://doi.org/10.1016/S0032-3861(02)00615-8

46. Zhu, X., Yan, D., In Situ FTIR spectroscopy study on the melting process of isotactic poly(propylene), Macromol. Chem. Phys. 202 (2001) 1109.

doi: https://doi.org/10.1002/15213935(20010401)202:7<1109::AID-MACP1109>3.0.CO; 2-1

47. Fann, D. M., Huang, S. K., Lee, J. Y., DSC studies on the crystallization characteristics of poly(ethylene terephthalate) for blow molding applications, Polym. Eng. Sci. 38 (1998) 265 doi: https://doi.org/10.1002/pen.10187

48. Laycock, B., Halley, P., Pratt, S., Werker, A., Lant, P., The chemomechanical properties of microbial polyhydroxyalkanoates, Prog. Polym. Sci. 39 (2014) 397. doi: https://doi.org/10.1016/j.progpolymsci.2013.06.008

49. Rehm, B. H. A., Bacterial polymers: biosynthesis, modifications and applications, Nat. Rev. Microbiol. 8 (2010) 578. doi: https://doi.org/10.1038/nrmicro2354

50. Montano-Herrera, L., Pratt, S., Arcos-Hernandez, M. V., Halley, P. J., Lant, P. A., Werker, A., Laycock, B., In-line monitoring of thermal degradation of PHA during melt-processing by near-infrared spectroscopy, $\mathbb{N}$. Biotechnol. 31 (2013) 357. doi: https://doi.org/10.1016/j.nbt.2013.10.005

51. Luef, K. P., Stelzer, F., Wiesbrock, F., Poly(hydroxy alkanoate)s in medical applications, Chem. Biochem. Eng. Q. 29 (2015) 287. doi: https://doi.org/10.15255/CABEQ.2014.2261

52. Ribeiro, P. L. L., Silva, G. S., Druzian, J. I., Evaluation of the effects of crude glycerol on the production and properties of novel polyhydroxyalkanoate copolymers containing high 11-hydroxyoctadecanoate by Cupriavidus necator IPT 029 and Bacillus megaterium IPT 429, Polym. Adv. Technol. 27 (2016) 542. doi: https://doi.org/10.1002/pat.3725

53. Mohapatra, S., Samantaray, D. P., Samantaray, S. M., Mishra, B. B., Das, S., Majumdar, S., Pradhan, S. K., Rath, S. N., Rath, C. C., Akthar, J., Achary, K. G., Structural and thermal characterization of PHAs produced by Lysinibacillus sp. through submerged fermentation process, Int. J. Biol. Macromol. 93 (2016) 1161. doi: https://doi.org/10.1016/j.ijbiomac.2016.09.077

54. Bengtsson, S., Pisco, A. R., Johansson, P., Lemos, P. C., Reis, M. A. M., Molecular weight and thermal properties of polyhydroxyalkanoates produced from fermented sugar molasses by open mixed cultures, J. Biotechnol. 147 (2010) 172. doi: https://doi.org/10.1016/j.jbiotec.2010.03.022

55. Gumel, A. M., Annuar, M. S. M., Heidelberg, T., Growth kinetics, effect of carbon substrate in biosynthesis of mclPHA by Pseudomonas putida Bet001, Braz. J. Microbiol. 45 (2014) 427. doi: https://doi.org/10.1590/S1517-83822014000200009

56. Sang-Hyeop, C., Jae-Hyop, S., Yousuf, J., Mohd, Z., HungSuck, $P$., Characterization of polyhydroxyalkanoates extracted from wastewater sludge under different environmental conditions, Biochem. Eng. J. 112 (2016) 1. doi: https://doi.org/10.1016/j.bej.2015.12.021 